\title{
Estudo qualitativo dos principais atributos que determinam a percepção de qualidade e de preço dos consumidores de restaurantes a la carte
}

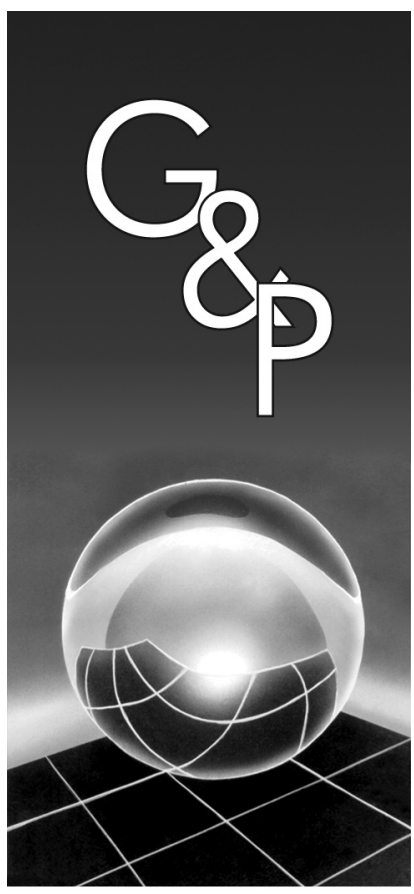

Maria Auxiliadora Cannarozzo Tinoco

José Luis Duarte Ribeiro

\begin{abstract}
Resumo
Este trabalho apresenta um estudo qualitativo dos principais determinantes da qualidade e do preço percebidos por clientes de restaurantes a la carte. Para isto, foram realizadas entrevistas em grupos focados, contemplando quatro tipos de consumidores avaliados (casais sem filhos, grupos de amigos, família e executivos). Os principais determinantes da qualidade percebida identificados foram: atributos da comida, atendimento, ambiente, tempo de espera, limpeza, segurança, instalações de apoio, cardápio, atributos da bebida, privacidade, exatidão, decoração e confirmação de expectativas. Realizou-se uma comparação com o modelo das dimensões da qualidade de Parasuraman et al. (1985) e propuseram-se algumas modificações baseadas nos resultados obtidos para o serviço de restaurantes a la carte e em outras pesquisas da literatura. Por outro lado, os determinantes mais importantes do preço percebido obtidos foram: qualidade da comida, decoração, ambiente, atendimento, instalações de apoio, cardápio, limpeza, atributos da bebida, quantidade das porções, expectativas prévias e privacidade. Os resultados obtidos sugerem a existência de relação entre os determinantes da qualidade percebida e preço percebido. Os resultados são comparados com outras pesquisas da literatura.
\end{abstract}

Palavras-chave: Serviços. Qualidade percebida. Preço percebido. Restaurantes a la carte.

\section{Introdução}

As economias dos países desenvolvidos e em desenvolvimento estão se tornando economias de serviços. Nos Estados Unidos, de cada 10 empregos 8 estão no setor de serviços, um dos poucos setores que geram um superávit de US $\$ 56$ bilhões por ano ao comércio exterior americano (CHADE, 2006). No Brasil, a tendência não se mostra diferente. Para o ano de 2003, o setor de serviços empregou $68,1 \%$ da população e foi responsável por aproximadamente $57 \%$ do PBI brasileiro (IBGE, 2003).

As empresas reconhecem que podem competir de modo mais eficaz, distinguindo-se pela qualidade dos serviços e pela maior satisfação de seus consumidores. A satisfação do cliente em relação a um produto ou serviço é influenciada de modo significativo pela avaliação que o consumidor faz de suas características (ZEITHAML, 2003). Diante deste cenário, é fundamental para as empresas de serviços aproximarem-se do cliente, conhecendo suas necessidades e expectativas, e identificando os atributos mais importantes do serviço oferecido.

A crescente importância do setor de serviços no contexto econômico mundial e a necessidade de conquistar clientes para garantir a sobrevivência no mercado demandam a identificação dos critérios segundo os quais os clientes avaliam a excelência do serviço. Dessa forma, o prestador de serviço pode priorizar seus esforços para atender aqueles atributos considerados mais importantes pelos clientes.

Autores concordam que, na ausência de evidências tangíveis, a avaliação que o cliente realiza do serviço depende de dimensões diferentes daquelas utilizadas para julgar a qualidade dos produtos (PARASURAMAN et al., 1985). A natureza destas dimensões tem sido estudada e diversas pesquisas têm sido direcionadas para desenvolver modelos de medição da qualidade em serviços, baseadas na avaliação de dimensões da qualidade, comumente denominadas determinantes da qualidade em serviços.

Além da qualidade percebida, outro fator que afeta o comportamento do consumidor de serviços, no que tange a sua satisfação e lealdade, é a percepção de preço (BEI; CHIAO, 2001). Poucas pesquisas têm estudado o preço percebido por clientes de serviços. De fato, as pesquisas encontradas na literatura sobre percepção de preço do serviço estão direcionadas ao estudo da relação 
entre o preço, qualidade percebida e outros determinantes da satisfação do cliente. Contudo, observa-se na literatura uma lacuna em relação aos fatores que geram ou afetam a percepção que os clientes de serviços possuem em relação ao preço.

Nesse contexto, este trabalho tem como objetivo principal identificar, através de entrevistas, os atributos que determinam as percepções dos clientes de restaurantes a la carte referentes a qualidade e preço. Entre os objetivos secundários está comparar as percepções dos diversos tipos de clientes de restaurantes a la carte avaliados em relação aos determinantes da qualidade e do preço.

\section{Qualidade percebida}

A qualidade percebida é definida como os julgamentos do consumidor sobre a excelência ou superioridade global do produto (ANDERSON et al., 1994; BEI; CHIAO, 2001). Para os serviços, a qualidade percebida pode ser definida como a avaliação que o cliente faz do serviço, durante ou após o término do processo. Esta avaliação se dá através da comparação entre o que o cliente esperava e o que ele percebeu do serviço prestado (GIANESI; CORRÊA, 1994).

A percepção de qualidade em serviços é diferente da qualidade real dos bens físicos, pois: (i) a primeira envolve um maior nível de abstração em lugar de atributos específicos dos produtos; e (ii) os consumidores emitem julgamentos sobre a qualidade do serviço baseando-se principalmente em critérios subjetivos (CHEN et al., 1994).

Conforme Parasuraman et al. (1985), para um melhor entendimento da qualidade do serviço é fundamental o reconhecimento das principais características do serviço: intangibilidade, heterogeneidade e inseparabilidade. Primeiro, porque devido à intangibilidade dos serviços resulta difícil para as empresas entender como os seus clientes percebem o serviço e como avaliam a qualidade do mesmo. Segundo, que os serviços variam de prestador para prestador, de cliente para cliente e de dia para dia. Esta inconsistência do serviço é fundamentada principalmente nos diferentes comportamentos das pessoas envolvidas no processo de prestação de serviço. Terceiro, considerando que grande parte dos serviços é produzida e consumida ao mesmo tempo, usualmente a avaliação da qualidade é realizada durante a entrega do serviço e na interação do cliente com o pessoal de contato da empresa prestadora de serviço. Neste contexto, a participação do cliente no processo de serviço afeta a qualidade do desempenho do serviço e o controle desta qualidade por parte da empresa.

Segundo Grönroos (1984), a avaliação da qualidade de um serviço está relacionada basicamente com aquilo que os clientes percebem desse serviço. Em relação a isto, Parasuraman et al. (1985) afirmam que as percepções da qualidade do serviço resultam da comparação entre as expectativas do cliente e o desempenho percebido do serviço. Bolton e Drew (1991) confirmaram essa afirmação através de uma pesquisa com serviços telefônicos residenciais, cuja percepção de qualidade dos clientes estava relacionada à não confirmação de suas expectativas em relação ao serviço prestado pela empresa telefônica.

\subsection{Determinantes da qualidade percebida do serviço}

Um dos primeiros pesquisadores que propôs um modelo para a medição da qualidade de serviço foi Grönroos (1984). Segundo esse autor, a qualidade percebida é função do serviço esperado, do serviço percebido e da imagem da empresa. De acordo com o modelo proposto por este autor, as dimensões ou os determinantes que são avaliados quando o consumidor adquire um serviço são: (i) qualidade técnica, resultado daquilo que é recebido durante a aquisição de um serviço e (ii) qualidade funcional, relativa ao nível de desempenho observado de forma subjetiva. Esta qualidade funcional é fortemente influenciada pela maneira como o serviço é prestado e depende do contato com o prestador de serviço. A imagem constitui a terceira dimensão de qualidade do modelo e abrange o local e os seus recursos disponíveis durante o consumo. Ela é construída pelas qualidades técnicas e funcionais, além de outros fatores como reputação, informações de terceiros, propaganda, preço e relações públicas.

No que concerne ao serviço dos restaurantes a la carte, os clientes utilizam três tipos de características de qualidade para julgar a experiência do serviço: (i) funcional, relacionada à qualidade da comida, variedade do cardápio, bebida, ingredientes, entre outros; (ii) mecânica, associada ao ambiente, layout, iluminação, decoração e instalações físicas; e (iii) humana, determinada pelo desempenho, comportamento e aparência dos funcionários (WALL; BERRY, 2007). Segundo esses autores, a qualidade humana exerce maior influência sobre a percepção global de qualidade dos clientes de restaurantes a la carte do que a qualidade mecânica. Em relação a isso, Parsa et al. (2005) afirmam que a funcionalidade constitui apenas uma parte da experiência de consumo do serviço, e uma combinação balanceada de atributos funcionais, mecânicos e humanos pode garantir o sucesso das empresas prestadoras deste tipo de serviço.

Parasuraman et al. (1985) propuseram um modelo para a medição da qualidade do serviço, baseado na comparação do serviço percebido com o serviço esperado. Um dos principais resultados de sua pesquisa foi que os consumidores utilizam os mesmos critérios para chegar a um julgamento sobre a qualidade do serviço prestado, independentemente do tipo de serviço considerado. Estes critérios foram agrupados em dez categorias denominadas de determinantes da qualidade do serviço ou 
dimensões da qualidade. A Figura 1 apresenta o modelo dos determinantes da qualidade dos serviços propostos por Parasuraman et al. (1985) e a descrição de cada determinante é ilustrada no Quadro 1.

Neste modelo, o cliente possui expectativas prévias para cada um dos determinantes da qualidade em relação ao serviço a ser adquirido. Estas expectativas são comparadas com o seu julgamento de desempenho para cada dimensão de qualidade, durante e após o processo de prestação de serviço, formando assim a percepção de qualidade do serviço. As expectativas são formadas principalmente através da comunicação boca-a-boca, das necessidades pessoais e da experiência anterior.

No mesmo ano, Berry et al. (apud JOHNSTON, 1995) encontraram um alto grau de correlação, por um lado entre os determinantes: comunicação, competência, cortesia, credibilidade e segurança, e por outro lado entre: acesso e compreensão e conhecimento do cliente. Os autores consolidaram estes determinantes em duas dimensões mais abrangentes, reduzindo desta forma os dez determinantes iniciais da qualidade do serviço a cinco determinantes: (i) confiabilidade; (ii) presteza; (iii) segurança; (iv) empatia; e (v) aspectos tangíveis (GIANESI; CORRÊA, 1994; MIGUEL; SALOMI, 2004).

Posteriormente, Parasuraman et al. (1988) utilizaram estes cinco determinantes como base para desenvolver o instrumento de medida da qualidade do serviço SERVQUAL, utilizado e citado por diversos autores (FITZSIMMONS; FITZSIMMONS, 2005, GIANESI; CORRÊA, 1994; KOTLER, 1996). Carman (apud CRONIN; TAYLOR, 1992) aplicou essa ferramenta em diversos serviços e concluiu que essas cinco dimensões não são consistentes e aplicáveis para todos os tipos de serviços. Continuando os estudos de medição

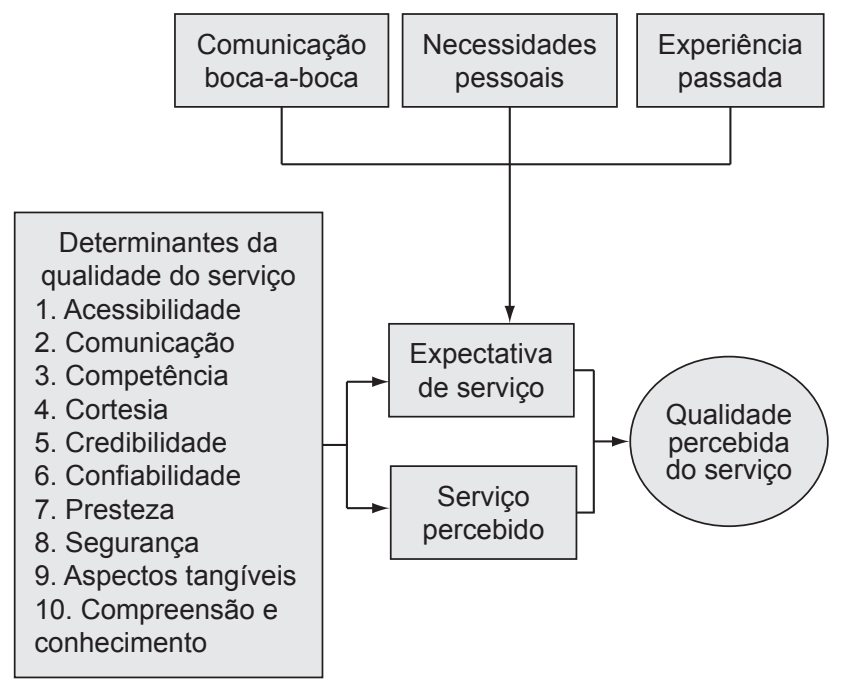

Figura 1. Determinantes da qualidade dos serviços. Fonte: adaptado de Parasuraman et al. (1985). da qualidade dos serviços, Cronin e Taylor (1992) propuseram o instrumento SERVPERF como uma alternativa para o instrumento SERVQUAL, baseado somente na percepção de desempenho dos serviços. Segundo esses autores, o SERVPERF explica melhor as variações de qualidade em relação às outras escalas testadas entre tipos de serviços.

Gianesi e Corrêa (1994) acreditam que o instrumento SERVQUAL, embora seja válido para compreender a forma como os clientes avaliam o serviço, propõe atributos que são excessivamente abrangentes para ajudar os responsáveis pela gestão das operações de serviços a tomarem decisões que tornem o serviço mais competitivo aos olhos dos consumidores. Estes autores definiram um conjunto de critérios para a avaliação da qualidade do serviço, combinando as visões de diferentes autores e outras observações empíricas, resultando em oito critérios tangíveis: consistência, competência, velocidade de atendimento, atendimento/atmosfera, flexibilidade, credibilidade, acesso e custo.

Os modelos aqui apresentados propõem diversos determinantes da qualidade dos serviços que podem auxiliar os gerentes de serviço na definição das estratégias mais adequadas para satisfazer os clientes. Porém, cada tipo de serviço pode ter determinantes que são considerados críticos para o setor, ou seja, que são mais importantes para os seus clientes. Portanto, os determinantes da qualidade têm graus de importância diferentes para cada tipo de serviço (SANTOS, 2000).

\section{Preço percebido}

Bei e Chiao (2001) definem o preço (desde o ponto de vista do consumidor) como aquilo que se renuncia ou que é sacrificado na obtenção de um produto. Quando o cliente percebe que o preço de um produto ou serviço é razoável, ele se sentirá mais satisfeito e manifestará intenções de repetir a compra. Por outro lado, se o consumidor sente que seu sacrifício não vale a pena, ele poderá não repetir a compra, mesmo que esteja satisfeito com a qualidade do produto ou serviço.

Chen et al. (1994) afirmam que a estimação de preços por parte dos clientes no ambiente de serviços é muito difícil, pois a grande maioria dos serviços oferece uma grande variedade de produtos. O preço destes produtos varia amplamente dentro de um tipo particular de indústria de serviços. Para eliminar essa dificuldade é utilizado o termo de preço percebido em lugar de preço. O preço percebido pode ser definido como o julgamento dos consumidores em relação ao preço médio de um serviço em comparação com o preço médio da concorrência.

O preço percebido inclui tanto elementos monetários quanto não monetários. Na indústria de serviços, o custo não monetário considera o tempo e o esforço do 
Quadro 1. Descrição dos determinantes da qualidade dos serviços. (Fonte: adaptado de PARASURAMAN et al., 1985).

\begin{tabular}{|c|c|}
\hline Determinante & Conceito \\
\hline Confiabilidade & $\begin{array}{l}\text { Envolve consistência de desempenho e confiabilidade. Significa que a empresa presta o serviço no momento } \\
\text { requerido e honra seus compromissos. Especificamente, abrange: precisão nas contas, manutenção dos } \\
\text { registros corretamente e realização do serviço no tempo designado. }\end{array}$ \\
\hline Presteza & $\begin{array}{l}\text { Refere-se ao desejo e presteza dos empregados em prover os serviços. Envolve rapidez nos serviços. } \\
\text { Exemplos: postar um recibo imediatamente, contatar um cliente rapidamente. }\end{array}$ \\
\hline Competência & $\begin{array}{l}\text { Significa possuir as habilidades necessárias e conhecimento para realizar o serviço, envolvendo: } \\
\text { conhecimento e habilidade do pessoal de contato, conhecimento e habilidade do pessoal de suporte } \\
\text { operacional e capacidade de pesquisa da organização. }\end{array}$ \\
\hline Acessibilidade & $\begin{array}{l}\text { Envolve proximidade e facilidade de contato. Significa que: o serviço pode ser facilmente acessível } \\
\text { por telefone, o tempo de espera para receber o serviço não é muito extenso e possui um horário de } \\
\text { funcionamento e localização convenientes. }\end{array}$ \\
\hline Cortesia & $\begin{array}{l}\text { Abrange educação, respeito, consideração e amabilidade do pessoal de contato. Inclui a consideração com os } \\
\text { bens dos clientes e a limpeza e boa aparência do pessoal de contato. }\end{array}$ \\
\hline Comunicação & $\begin{array}{l}\text { Significa manter os clientes informados em linguagem que sejam capazes de compreender. Pode significar } \\
\text { que a empresa deve ajustar sua linguagem para diferentes consumidores - aumentando o nível de sofisticação } \\
\text { para os mais bem educados e conversando de maneira simples e direta com os mais simples. Também } \\
\text { envolve: proporcionar explicação do serviço, preços, escolhas entre serviço e custo e garantir ao consumidor } \\
\text { que um eventual problema será resolvido. }\end{array}$ \\
\hline Credibilidade & $\begin{array}{l}\text { Considera a honestidade e implica que empresa esteja comprometida em atender aos interesses e objetivos } \\
\text { dos clientes. Inclui: nome e reputação da empresa, características do pessoal de contato e nível de interação } \\
\text { com os clientes. }\end{array}$ \\
\hline Segurança & Significa ausência de perigo, risco ou dúvida. Envolve: segurança física, financeira e confidencialidade. \\
\hline $\begin{array}{l}\text { Compreensão e } \\
\text { conhecimento do cliente }\end{array}$ & $\begin{array}{l}\text { Envolve esforçar-se para compreender as necessidades dos clientes, considerando o aprendizado sobre } \\
\text { os requisitos específicos do cliente, proporcionar atenção individualizada e reconhecimento dos clientes } \\
\text { regulares. }\end{array}$ \\
\hline Aspectos tangíveis & $\begin{array}{l}\text { Inclui as evidências físicas do serviço, tais como: instalações, aparência do pessoal, ferramentas e } \\
\text { equipamentos utilizados no serviço, representações físicas do serviço como cartão de crédito plástico ou } \\
\text { uma prestação de contas, além de outros clientes presentes no serviço. }\end{array}$ \\
\hline
\end{tabular}

consumidor envolvido na aquisição do serviço. Serviços com características inovadoras para reduzir o tempo e o esforço por parte do cliente podem aumentar o valor percebido do serviço, e em conseqüência, reduzir o preço percebido (CHEN et al., 1994).

Conforme Sheth et al. (2001), a psicofísica dos preços envolve complexos processos perceptuais do cliente. Esta psicofísica se refere a como os clientes percebem os preços em termos psicológicos e está fundamentada em três aspectos: preço de referência, assimilação e contraste, e preço como uma pista de qualidade.

O preço de referência é o preço que os clientes esperam pagar. Se o preço real é menor que o preço de referência, ele é percebido como um bom valor econômico. Com ou sem propaganda, todas as pessoas têm em mente um preço de referência para um produto ou serviço, o qual elas acreditam ser o preço certo. Conforme Kotler (1996), o preço de referência pode ser formado pela percepção de preços atuais, preços anteriores ou pelo contexto de compra.

O princípio da assimilação e contraste sugere que os clientes têm uma faixa de aceitação e rejeição, de modo que os preços que caem dentro da faixa de aceitação são assimilados e os que caem dentro da faixa de rejeição são contrastados e rejeitados.
Por outro lado, o preço é utilizado muitas vezes como uma pista de qualidade, ou seja, como uma base para inferência sobre a qualidade do produto ou serviço. Segundo Sheth et al. (2001), o uso do preço como pista de qualidade acontece especialmente quando a qualidade não pode ser julgada facilmente e independentemente do preço. Neste contexto, alguns pesquisadores têm estudado a existência de relação entre a qualidade percebida e o preço percebido pelos clientes. Resultados sugerem que existe uma relação positiva entre o preço e a qualidade percebida (e.g. MONROE; KRISHNAN apud SHETH et al., 2001; CHEN et al., 1994).

\section{Método de pesquisa}

A presente pesquisa exige levantar as impressões e sugestões dos agentes envolvidos para a identificação dos determinantes da percepção de qualidade e preço dos serviços de restaurantes a la carte. Para tanto, optou-se por adotar um procedimento qualitativo na coleta e tratamento dos dados. Dentro da abordagem qualitativa, selecionou-se a técnica de entrevistas em grupos focados para o levantamento dos dados. As entrevistas em grupos focados são utilizadas para gerar idéias e percepções 
de um grupo de pessoas sobre um assunto, propiciam riqueza e flexibilidade na coleta de dados e favorecem a espontaneidade através da interação entre os participantes (RIBEIRO, 2003).

A metodologia dos grupos focados utilizada neste estudo foi dividida nas seguinte etapas: (i) planejamento e (ii) condução das entrevistas. No planejamento são identificados: o objetivo do estudo, a definição dos participantes, o local, as questões e o moderador. $\mathrm{Na}$ condução das entrevistas são definidas as formas de armazenamento dos dados coletados nestas e é planejado o roteiro das sessões, o qual deve ser padrão para cada sessão.

O objetivo principal do estudo em grupos focados foi a identificação dos principais determinantes que afetam a percepção de qualidade e de preço do ponto de vista dos consumidores de restaurantes a la carte. Considerando que as necessidades e expectativas dos clientes e, em conseqüência, a avaliação que eles fazem da qualidade do serviço, variam em função do motivo de utilização do serviço, a partir de um contato preliminar com gerentes de restaurantes, foram identificadas quatro categorias de consumidores: (i) casais sem filhos; (ii) grupos de amigos; (iii) famílias; e (iv) executivos. Essa categorização foi utilizada como critério na realização dos grupos focados. Dessa forma, a pesquisa buscou comparar os atributos mais importantes que geram a percepção de qualidade e de preço dos consumidores de restaurantes a la carte, sob a ótica dos diferentes tipos de clientes.

Os grupos focados se constituíam por pessoas que podem ser caracterizadas como clientes ativos de restau- rantes a la carte, moradores de Porto Alegre e das classes sociais A e B, pois grande parte dos consumidores de restaurantes a la carte pertence a essas classes sociais. As entrevistas foram realizadas utilizando quatro grupos focados, um para cada categoria de clientes, obedecendo aos estratos de sexo e idade apresentados na Tabela 1.

O número de participantes em cada grupo (6) foi o suficiente para todos terem a oportunidade de opinar em relação ao assunto e também para fornecer diversidade de idéias (RIBEIRO, 2003). As entrevistas seguiram um roteiro semi-estruturado, com questões abertas induzindo à participação dos entrevistados. A estrutura do roteiro de questões está apresentada no Quadro 2.

Assim, foi selecionado um grupo de pessoas caracterizadas dentro das categorias e estratos definidos no planejamento da entrevista, para participar dos grupos focados. As entrevistas foram conduzidas nas salas do prédio da Universidade, local de fácil acesso aos participantes e que possui a estrutura física adequada para a melhor disposição (em círculo) dos entrevistados, facilitando a comunicação entre eles. As sessões tiveram duração aproximada de uma hora e meia; tempo suficiente para o levantamento dos dados e para a participação de todos.

O procedimento para o armazenamento dos dados foi a gravação com vídeo, o que facilitou a identificação de cada um dos membros do grupo no momento em que estavam falando. Também, contou-se com a presença de um auxiliar, localizado em uma mesa lateral, que anotava as intervenções dos participantes.

Tabela 1. Planejamento das entrevistas de grupos focados.

\begin{tabular}{cccccc}
\hline \multirow{2}{*}{ Grupos } & Categorias de clientes & \multicolumn{4}{c}{ Idade } \\
\cline { 3 - 6 } & & \multicolumn{2}{c}{$\mathbf{2 5 - 4 0}$ anos } & \multicolumn{2}{c}{ 40 anos } \\
\cline { 2 - 5 } & & 2 & 1 & Feminino & Masculino \\
\hline 1 & Casais sem filhos & 1 & 2 & 2 & 2 \\
2 & Grupos de amigos & 1 & 2 & 2 & 1 \\
3 & Famílias & 2 & 1 & 1 & 2 \\
4 & Executivos & & & \\
\hline
\end{tabular}

Quadro 2. Roteiro de questões para as entrevistas de grupos focados.

\begin{tabular}{|c|c|}
\hline Itens & Questões \\
\hline Caracterização do cliente & $\begin{array}{l}\text { - Qual a freqüência de utilização do serviço? } \\
\text { - Qual o tipo de refeição que normalmente faz no restaurante a la carte? } \\
\text { - Quais são os critérios para a escolha de um restaurante a la carte? }\end{array}$ \\
\hline $\begin{array}{l}\text { Determinantes da qualidade } \\
\text { percebida }\end{array}$ & $\begin{array}{l}\text { - Em sua opinião, o que caracteriza um restaurante a la carte de qualidade? } \\
\text { - Quais são os principais fatores que afetam a qualidade percebida do serviço? } \\
\text { - Quais desses fatores têm maior e menor impacto na percepção da qualidade? }\end{array}$ \\
\hline $\begin{array}{l}\text { Determinantes do preço } \\
\text { percebido }\end{array}$ & $\begin{array}{l}\text { - Como é formada a percepção do preço em relação ao serviço oferecido por um restaurante a la } \\
\text { carte? } \\
\text { - Quais são os principais fatores que afetam a percepção de preço do serviço? } \\
\text { - Quais desses fatores têm maior e menor impacto na percepção de preço? }\end{array}$ \\
\hline
\end{tabular}




\section{Descrição das entrevistas}

As entrevistas foram realizadas para os quatro grupos focados identificados na Tabela 1 . O primeiro grupo foi constituído por pessoas que, na maioria dos casos, freqüentam os restaurantes a la carte em companhia de namorado/a ou esposo/a. O segundo grupo foi constituído por pessoas que geralmente freqüentam estes estabelecimentos para reuniões com amigos. O terceiro grupo foi formado por pessoas que utilizam o serviço de restaurante a la carte em companhia de seu esposo/a e filhos (principalmente crianças), e o quarto grupo se constituía de clientes que frequientam restaurantes a la carte por motivo de trabalho (executivos). Cada grupo reuniu seis participantes estratificados em relação ao sexo e idade segundo a Tabela 1.

\subsection{Casais sem filhos}

\subsubsection{Freqüência de utilização do serviço e tipo de refeição}

Os participantes apontaram que a freqüência de utilização varia entre 5 a 16 vezes por mês. Para a maioria dos participantes, os dias de maior uso do serviço são aos finais de semana. O tipo de refeição que os participantes realizam no restaurante a la carte com seus pares é principalmente o jantar. Contudo, alguns membros citaram que também utilizam o serviço, eventualmente, para almoçar durante os finais de semana.

\subsubsection{Critérios para a escolha e características de um restaurante a la carte de qualidade}

Alguns critérios para a escolha de um restaurante a la carte que foram indicados pelo grupo são: a possibilidade de experimentar pratos novos e conhecer outros estabelecimentos, a localização do restaurante e a segurança do local - relacionada fundamentalmente com a presença de estacionamento. Também foi assinalado como critério de escolha de um restaurante a la carte o respeito à cultura nos restaurantes de comida típica de um país ou região.

Outros critérios citados que também foram mencionados como características de um restaurante a la carte de qualidade foram: o atendimento diferenciado dos funcionários, a qualidade e sabor da comida, o requinte do cardápio, o ambiente acolhedor e aconchegante (sem barulho), a separação bem definida das mesas para fumantes e não fumantes (de modo que a fumaça não afete os não fumantes), a imagem e a recomendação de amigos e conhecidos. Outros atributos de qualidade, segundo o grupo, são: uma boa carta de vinhos em variedade e marcas, o tempo razoável para servir e para entregar a conta, a aparência da mesa (prataria, talheres adequados e bem apresentáveis, guardanapo de toalha e papel), o conhecimento do garçom em relação à preparação dos pratos, ingredientes e vinhos, os couverts diferenciados, uma recepção calorosa (muitas vezes realizada pelo próprio dono do restaurante) e a variedade dos pratos.

\subsubsection{Fatores que afetam a qualidade percebida}

Entre os atributos principais que afetam a percepção de qualidade dos clientes que utilizam o serviço de restaurante a la carte com seus pares, foram levantados: o sabor da comida; a qualidade dos ingredientes, sendo considerada importante a disponibilidade de azeite de oliva extra virgem para as saladas e frutos de mar frescos quando forem oferecidos; o requinte do cardápio; a elaboração das receitas; a apresentação colorida do prato; o atendimento dos funcionários; a recepção; o ambiente acolhedor (com iluminação e decoração adequadas); a limpeza do local; o acolhimento do garçom; a privacidade para o casal e a disponibilidade de fio dental no banheiro. Outros atributos mencionados que podem afetar negativamente a percepção de qualidade são: a segurança ostensiva, com guardas armados na recepção do local (que muitas vezes assustam os próprios clientes); o tempo de espera para ingressar no local, fazer os pedidos e recebê-los; os cheiros da cozinha no ambiente e a ineficiência na hora de emitir a conta.

Outros fatores que foram mencionados como atributos que possuem menor impacto na percepção de qualidade dos clientes são: a possibilidade de reserva com certa tolerância e a localização, justificando que quando o cliente gosta de um determinado restaurante a la carte o deslocamento requerido é compensado com os benefícios recebidos e a obrigatoriedade da gorjeta $(10 \%)$. Um dos atributos mencionados que gerou divergências de opiniões foi o preço. Contudo, para a maioria dos participantes o efeito do preço na percepção de qualidade dos clientes de restaurantes a la carte é pouco importante.

\subsubsection{Fatores que afetam a percepção de preço dos clientes}

Entre os fatores que afetam a percepção de preço dos clientes categorizados como casais sem filhos, o grupo considerou que os de maior importância são: a sofisticação do ambiente; a decoração; o atendimento dos funcionários; a elaboração do cardápio; a limpeza do local e dos banheiros; a qualidade e requinte da comida; a exclusividade de certos pratos oferecidos; a qualidade dos ingredientes e insumos para a preparação dos pratos e a aparência da mesa (prataria, toalhas de mesa, copos e guardanapos).

Outros fatores mencionados que podem afetar a percepção de preço são: a privacidade; a obrigatoriedade 
de gorjeta e a segurança do local, incluindo a disponibilidade de estacionamento.

\subsection{Grupos de amigos}

\subsubsection{Freqüência de utilização do serviço e tipo de refeição}

A frequiência de utilização de restaurantes a la carte, apontada pelo grupo entrevistado, variou entre 2 a 15 vezes por mês. Alguns utilizam o serviço durante a semana com os colegas de trabalho ou estudo, já outros, somente durante o final de semana. Alguns entrevistados relataram que utilizam o serviço de restaurantes a la carte com seus amigos para o almoço e outros para o jantar. Os almoços com amigos acontecem geralmente durante a semana e os jantares principalmente no final de semana.

\subsubsection{Critérios para a escolha e características de um restaurante a la carte de qualidade}

Entre os critérios citados pelo grupo para a escolha de um restaurante a la carte estão: o preço do serviço; o tipo de comida; o tamanho da porção e a conveniência na localização, especificamente para o almoço (já que no jantar ela não é considerada como critério de escolha).

Outros critérios citados pelo grupo entrevistado e também considerados como características de um restaurante a la carte de qualidade são: a comida; o atendimento diferenciado dos funcionários; o ambiente; a variedade de pratos oferecidos; a disponibilidade de pratos e bebidas colocadas no cardápio e a segurança, determinada principalmente pela disponibilidade de estacionamento.

\subsubsection{Fatores que afetam a qualidade percebida}

Os principais fatores que afetam a percepção de qualidade dos clientes de restaurantes a la carte entrevistados são: os atributos da comida e das bebidas (temperatura, temperos, ingredientes); a cortesia dos funcionários; a comparação entre o serviço esperado e o recebido (confirmação das expectativas); o tempo de entrega da comida e das bebidas e a exatidão (eficiência) do serviço como um todo. Em relação a esse último item, os membros do grupo mencionaram que erros no cálculo da conta e no pedido realizado comprometem a qualidade do serviço oferecido pelos restaurantes. Outros fatores citados foram: a segurança; a organização (layout) do local (e.g. espaçamento adequado entre mesas; fumantes bem separados dos não fumantes); os cheiros (e.g. comida; fumaça) no ambiente; a limpeza; as instalações de apoio (e.g. banheiro, mesas, cadeiras) e a iluminação.

Outros fatores indicados pelos participantes como atributos de menor efeito na percepção de qualidade são: a privacidade para conversar; o preço do serviço; a rapidez no atendimento do garçom e a cozinha aberta para visitação. Um dos participantes comentou que o serviço pós-venda que alguns restaurantes a la carte oferecem também pode afetar a qualidade percebida pelos clientes, citando como exemplos: a preocupação com as insatisfações dos clientes e o desconto oferecido para uma próxima compra a um cliente insatisfeito.

\subsubsection{Fatores que afetam a percepção de preço dos clientes}

Entre os principais fatores que afetam a percepção de preço dos clientes de restaurantes a la carte que utilizam o serviço com amigos, foram citados: a qualidade da comida e das bebidas; o ambiente do local - incluindo a decoração e as instalações de apoio; a relação custobenefício e o atendimento dos funcionários.

Entre os atributos de menor efeito na percepção de preço dos clientes, foram mencionados: a imagem do restaurante - formada através da propaganda e divulgação, a quantidade das porções e a apresentação da comida.

\subsection{Famílias}

\subsubsection{Freqüência de utilização do serviço e tipo de refeição}

O grupo entrevistado, caracterizado como família, freqüenta restaurantes a la carte em média entre 1 a 2 vezes por mês. Foi comentado que esse tipo de restaurante não é o mais usado por famílias com filhos pequenos, pois geralmente elas precisam de um local para realizar uma refeição rápida e que ofereça opções para todos os membros da família. O tipo de refeição que comumente os participantes realizam nos restaurantes a la carte é o almoço.

\subsubsection{Critérios para a escolha e características de um restaurante a la carte de qualidade}

Os entrevistados concordaram quanto aos seguintes critérios, também considerados como características de qualidade, para a escolha de um restaurante a la carte: a comida excelente em sabor e apresentação; o bom atendimento dos funcionários (com simpatia, respeito e rapidez); o ambiente agradável, tranqüilo, sem área para fumantes e sem cheiros fortes e as instalações (salão, banheiros e cozinha) perfeitamente limpas.

Outros atributos que podem ser considerados de qualidade, para os clientes que utilizam o serviço com a família (casal que está acompanhado de filhos ou mesmo outros parentes), são: as opções oferecidas para a distração das crianças, como por exemplo, uma área com brinquedos e com recreacionista; iluminação adequada; variedade de pratos (incluindo opções simples que as crianças gostam); possibilidade de porções menores; local prático, não muito caro e com estacionamento e segurança para a família. Outra das características citadas que caracterizariam um restaurante a la carte de qualidade é a disponibili- 
dade de instalações adequadas para crianças, como por exemplo, cadeirinhas confortáveis e seguras, trocador nos banheiros, e talheres, copos e pratos adequados para crianças. Contudo, esse último atributo é muito difícil de ser observado neste tipo de serviço. Segundo os entrevistados, muito poucos restaurantes a la carte possuem todas as características mencionadas, e de fato a grande maioria desses estabelecimentos não está preparada para atender às necessidades e expectativas dos clientes que utilizam o serviço com crianças.

\subsubsection{Fatores que afetam a qualidade percebida}

Entre os principais fatores que afetam a percepção de qualidade dos clientes de restaurantes a la carte que utilizam o serviço com seu/sua esposo/a e filhos, foram mencionados: a comida (sabor, apresentação e temperatura); a variedade de pratos; o atendimento dos funcionários (cortesia, respeito e sensibilidade); a relação custo-benefício; o ambiente; as instalações físicas; a segurança; a apresentação dos talheres, da toalha de mesa, dos copos e pratos e o tempo de atendimento, incluindo o serviço de comidas e bebidas. Esse item foi considerado importante, pois geralmente as crianças não têm muita paciência para esperar a comida e não conseguem ficar sentadas durante muito tempo. O layout do local também foi considerado entre os fatores que afetam a qualidade percebida, visto que muitas vezes os pais precisam levar o carrinho da criança e não conseguem transitar devido à grande quantidade de mesas. Finalmente, os itens: limpeza do local e apresentação do garçom também foram considerados importantes.

Outros fatores de menor influência na qualidade percebida mencionados pelo grupo foram: a conveniência do restaurante, a exatidão no cálculo da conta e a quantidade das porções. Em relação a esse último, foi acrescentado que alguns restaurantes que não oferecem uma porção menor para a criança, às vezes, têm a opção do prato família, que pode ser dividido entre todos os integrantes da mesma, incluindo as crianças. Outro fator citado pelo grupo (como fator de menor efeito na percepção de qualidade dos clientes família) foi o preço do serviço.

\subsubsection{Fatores que afetam a percepção de preço dos clientes}

De acordo com os participantes do grupo, a percepção de preço nos clientes é formada principalmente por: comparação com restaurantes similares (concorrência); visual do restaurante; sofisticação do ambiente; localização do restaurante; apresentação do garçom e demais funcionários; decoração; indicação de amigos; artigos em revistas; propaganda e pessoas que freqüentam o local. Entre os principais fatores que afetam a percepção de preço dos clientes que utilizam o serviço com sua família, foram mencionados: a qualidade da comida; o ambiente; o atendimento; as instalações físicas; a quantidade das porções; a decoração do local e a limpeza.

Os atributos de menor efeito na percepção de preço que o grupo destacou foram: a elaboração do cardápio e a disponibilidade de estacionamento.

\subsection{Executivos}

\subsubsection{Freqüência de utilização do serviço e tipo de refeição}

O grupo entrevistado, caracterizado como clientes executivos de restaurantes a la carte, utiliza o serviço com uma freqüência que varia entre 1 a 8 vezes por mês, principalmente durantes os dias laborais. A freqüência de utilização do serviço depende dos objetivos e da programação de cada um dos executivos com seus clientes. O tipo de refeição que comumente os executivos entrevistados compartilham com seus clientes é o almoço. O horário de almoço é mais conveniente tanto para os executivos quanto para seus clientes. Contudo, eventualmente são realizados jantares para comemoração de benefícios gerados da negociação, em datas especiais ou ainda para a entrega de prêmios e reconhecimentos.

\subsubsection{Critérios para a escolha e características de um restaurante a la carte de qualidade}

Conforme os participantes do grupo, os principais critérios para a escolha de um restaurante a la carte são: a conveniência do local; a indicação de terceiros; a privacidade do local; a disponibilidade de estacionamento; a relação custo-benefício e a preferência do cliente por um restaurante ou comida específica. Muitos executivos escolhem um determinado restaurante pela indicação de seu cliente.

Outros critérios de escolha também considerados como características de qualidade pelo grupo entrevistado foram: ambiente tranqüilo e acolhedor; comida saborosa e bem apresentada, com temperos diferenciados e porção adequada; o atendimento dos funcionários; a disponibilidade de mesas na entrada (ou uma boa recepção para os clientes em espera) e a discrição do garçom para manter uma conversa sem interferências.

Do ponto de vista dos clientes executivos, um restaurante a la carte de qualidade também é caracterizado pelo layout do local, com espaço adequado para circulação; pela temperatura adequada do ambiente, ,sem área de fumantes; pela iluminação adequada; pela limpeza do local, sem cheiros; pelo tempo de resposta e pela variedade do cardápio.

\subsubsection{Fatores que afetam a qualidade percebida}

Os principais fatores citados que afetam a percepção de qualidade dos clientes executivos de restaurantes a la carte foram: a apresentação da comida, a temperatura 
da bebida e a elaboração dos pratos. Em relação a este último, foi comentado que o cardápio de um restaurante a la carte deve oferecer pratos diferenciados, “...cuidadosamente elaborados e a partir de ingredientes e temperos diferenciados...". Outros fatores que foram considerados como determinantes da qualidade percebida dos clientes são: o comportamento do garçom, referindo-se principalmente ao tempo de resposta no atendimento e às interrupções inoportunas de muitos funcionários; a limpeza do local (incluindo os banheiros); o tempo de espera (na entrada, no serviço de comida e bebidas e na entrega da conta); os cheiros do local; a privacidade e tranqüilidade do local e o ambiente.

Entre os fatores de menor efeito na percepção de qualidade, do ponto de vista do grupo entrevistado, foram mencionados: a obrigatoriedade da gorjeta; o preço; o layout do local (espaço para circulação); a decoração; a disponibilidade de estacionamento e a adequação das instalações de apoio (mesas, cadeiras, copos, talheres, pratos, toalha de mesa e guardanapos de tela).

\subsubsection{Fatores que afetam a percepção de preço dos clientes}

De acordo com os participantes, a percepção de preço é formada na mente dos clientes executivos de restaurantes a la carte a partir do cardápio oferecido, da propaganda do estabelecimento, da indicação de terceiros, da imagem do restaurante, de experiências e expectativas anteriores dos clientes, da decoração do local, da localização do restaurante e do reconhecimento do chefe de cozinha e das pessoas que freqüentam o local.

Entre os fatores de maior efeito na percepção de preço dos clientes executivos, foram citados: a qualidade do serviço e a qualidade da comida (incluindo o sabor e a aparência, a sofisticação e especialidade do local e a elaboração do cardápio); a decoração do local e as expectativas prévias dos clientes. Foram levantados também como atributos que influenciam o preço percebido pelos clientes: o ambiente, a quantidade e organização das mesas, a forma de atendimento, a condução à mesa, a disponibilidade de manobrista, as instalações de apoio utilizadas, os bens facilitadores disponibilizados (como, por exemplo, fio dental no banheiro) e a privacidade do local. Outros atributos de menor efeito na percepção de preço destes clientes e que foram citados são: a quantidade das porções, a iluminação, a disponibilidade de carta de vinhos, as experiências anteriores e o número de funcionários.

\section{Análise dos resultados das reuniões}

A análise dos dados coletados é realizada comparando-se as opiniões apresentadas pelos participantes dos quatro grupos focados (casais sem filhos, grupos de amigos, família e executivos). Esta comparação entre os grupos segue o esquema de perguntas estabelecido no roteiro do Quadro 4.

\subsection{Caracterização do cliente}

As primeiras três questões tiveram como objetivo caracterizar os grupos entrevistados como clientes de restaurantes a la carte e ambientar os participantes no assunto de discussão.

Em relação à freqüência de utilização do serviço de restaurantes a la carte, observou-se que existe grande variabilidade nas respostas dos participantes de cada grupo, com exceção do grupo família, no qual a maioria dos participantes apontou uma freqüência similar de utilização do serviço. De uma forma geral, poder-se-ia dizer que os clientes que mais freqüentam restaurantes a la carte são os casais sem filhos e os grupos de amigos.

$\mathrm{O}$ tipo de refeição que geralmente realizam os clientes nos restaurantes a la carte foi característico de cada grupo. O grupo caracterizado como casais sem filhos indicou que geralmente utiliza este serviço no jantar. O grupo de amigos apontou procurar este tipo de estabelecimento tanto para o almoço quanto para o jantar. Já os grupos 'família' e 'executivos' indicaram o almoço como principal tipo de refeição realizada nos restaurantes a la carte.

Em relação aos critérios de escolha de um restaurante a la carte, pode ser ressaltado que a maioria deles foram considerados entre os atributos que caracterizam um restaurante a la carte de qualidade e, entre os fatores que afetam a qualidade e o preço percebidos dos clientes entrevistados. Outros critérios de escolha característicos de cada grupo de clientes entrevistados podem ser mencionados: para o grupo caracterizado como 'casais sem filhos' destacaram-se a possibilidade de experimentar pratos novos e o respeito cultural como critérios de escolha; para o grupo 'família' são importantes as opções oferecidas para a distração das crianças e a praticidade do local e, para o grupo de clientes executivos foram relevantes as preferências de seus clientes e a disponibilidade de mesas.

\subsection{Determinantes da qualidade percebida}

Partindo da análise das perguntas 4, 5 e 6 em relação às características de um restaurante a la carte de qualidade e aos fatores que afetam a qualidade percebida do ponto de vista dos grupos entrevistados, identificaram-se os principais atributos e outros fatores menos importantes que afetam a percepção de qualidade dos clientes de restaurantes a la carte caracterizados nos quatro grupos estudados: casais sem filhos, grupos de amigos, família e executivos.

Os quatro grupos coincidiram nos seguintes fatores importantes que afetam a percepção de qualidade dos clientes de restaurantes a la carte: os atributos da 
comida (incluindo sabor, apresentação, temperatura e ingredientes); o atendimento dos funcionários (cortesia, simpatia, respeito, discrição, conhecimento e sensibilidade); o ambiente (incluindo layout, pessoas que freqüentam o local, cheiros, separação de fumantes e não fumantes, tamanho do local e iluminação); o tempo de espera (encaminhamento à mesa, serviço de refeições e bebidas e entrega da conta) e a limpeza do local.

Outros fatores apresentaram algumas divergências entre os grupos: a segurança, relacionada principalmente com a presença de estacionamento, e as instalações de apoio (adequação de mesas, pratarias, cadeiras, toalhas de mesa, guardanapos, banheiros, copos, instalações para crianças, entre outras) foram consideradas pelos grupos 'casais sem filhos', 'grupos de amigos' e 'família', como fatores importantes que afetam a percepção de qualidade. Contudo, estes atributos foram incluídos entre os de menor efeito pelo grupo de executivos. Por outro lado, o cardápio (incluindo a elaboração das receitas e a variedade de pratos) foi incluído como atributo importante pelos grupos 'casais sem filhos', 'família' e 'executivos'. Porém, este último fator foi indicado como de menor importância pelo grupo de amigos.

O Quadro 3 resume a comparação dos fatores de maior e menor efeito na qualidade percebida dos clientes apontados pelos grupos entrevistados. É importante ressaltar que o Quadro 3 apresenta os atributos que afetam a qualidade percebida na ordem de importância geral, obtida da média dos grupos, e não na ordem indicada por cada grupo individual, isto para que seja facilitada a comparação visual entre os atributos apontados por cada grupo.

\subsection{Determinantes do preço percebido}

As últimas três questões realizadas nas entrevistas procuraram identificar os determinantes do preço percebido pelos clientes de restaurantes a la carte, do ponto de vista dos participantes dos grupos focados.

Os quatro grupos coincidiram nos seguintes fatores importantes que afetam a percepção de preço dos clientes de restaurantes a la carte: a qualidade da comida, o ambiente, a decoração e o atendimento. As instalações de apoio foram incluídas também como atributo importante pelos grupos 'casais sem filhos', 'grupos de amigos' e 'família', mas não foram consideradas pelo grupo de executivos.

Os grupos de casais sem filhos e executivos apontaram também o cardápio como fator importante que afeta a percepção de preço, contudo, o grupo família considerou este atributo entre os de menor importância. Por outro lado, observou-se convergência entre o grupo 'casais sem filhos' e 'família' ao considerar o atributo 'limpeza do local' entre os fatores importantes que afetam a percepção de preço dos clientes. Outros fatores de importância mencionados pelos grupos, sem existir convergências entre eles, foram: os atributos da bebida, a quantidade das porções e a privacidade.

O Quadro 4 resume a comparação dos fatores de maior e menor efeito no preço percebido pelos clientes, obtida pelas entrevistas de grupos focados. De igual forma que para a qualidade percebida, são apresentados os atributos que afetam o preço percebido na ordem de importância geral, obtidos da média dos grupos e não na ordem indicada por cada grupo individual.

Quadro 3. Comparação dos determinantes da qualidade percebida entre os grupos entrevistados.

\begin{tabular}{|c|c|c|c|}
\hline \multicolumn{4}{|c|}{ Fatores importantes que afetam a qualidade percebida } \\
\hline \multicolumn{4}{|c|}{ Grupos } \\
\hline Casais sem filhos & Grupos de amigos & Família & Executivos \\
\hline Decoração & Exatidão & Cardápio & Cardápio \\
\hline Exatidão & Confirmação de expectativas & Instalações de apoio & Privacidade \\
\hline Privacidade & Atributos da bebida & Segurança & Atributos da bebida \\
\hline Cardápio & Instalações de apoio & Limpeza & Limpeza \\
\hline Instalações de apoio & Segurança & Tempo de espera & Tempo de espera \\
\hline Segurança & Limpeza & Ambiente & Ambiente \\
\hline Limpeza & Tempo de espera & Atendimento & Atendimento \\
\hline Tempo de espera & Ambiente & Atributos da comida & Atributos da comida \\
\hline Ambiente & Atendimento & & \\
\hline Atendimento & Atributos da comida & & \\
\hline Atributos da comida & & & \\
\hline \multicolumn{4}{|c|}{ Outros fatores (menos importantes) que afetam a qualidade percebida } \\
\hline Imagem & Localização & Localização & Localização \\
\hline Carta de vinhos & Preço & Preço & Preço \\
\hline Propaganda & Cardápio & Quantidade das porções & Segurança \\
\hline Possibilidade de reserva & Cozinha para visitação & Exatidão & Instalações de apoio \\
\hline Preço & Privacidade & & Decoração \\
\hline Localização & Pós-venda & & \\
\hline
\end{tabular}


Quadro 4. Comparação dos determinantes do preço percebido entre os grupos entrevistados

\begin{tabular}{|c|c|c|c|}
\hline \multicolumn{4}{|c|}{ Fatores importantes que afetam a percepção de preço } \\
\hline \multicolumn{4}{|c|}{$\begin{array}{c}\text { Grupos } \\
\end{array}$} \\
\hline Casais sem filhos & Grupos de amigos & Família & Executivos \\
\hline Qualidade da comida & Qualidade da comida & Qualidade da comida & Qualidade da comida \\
\hline Decoração & Decoração & Decoração & Decoração \\
\hline Ambiente & Ambiente & Ambiente & Ambiente \\
\hline Atendimento & Atendimento & Atendimento & Atendimento \\
\hline Instalações de apoio & Instalações de apoio & Instalações de apoio & Expectativas prévias \\
\hline Cardápio & Atributos da bebida & Quantidade das porções & Cardápio \\
\hline Limpeza & & Limpeza & Privacidade \\
\hline \multicolumn{4}{|c|}{ Outros fatores (menos importantes) que afetam a percepção de preço } \\
\hline Segurança & Imagem & Segurança & Imagem \\
\hline Privacidade & Quantidade das porções & Cardápio & Quantidade das porções \\
\hline Carta de vinhos & & Concorrência & Carta de vinhos \\
\hline Obrigatoriedade da gorjeta & & Localização & Localização \\
\hline & & Propaganda & Propaganda \\
\hline & & Apresentação dos funcionários & Número de funcionários \\
\hline & & & Experiências anteriores \\
\hline
\end{tabular}

\section{Interpretação dos resultados}

\subsection{Determinantes da qualidade percebida}

A análise dos resultados obtidos nos diversos grupos revelou concordância em relação aos principais determinantes da qualidade percebida em restaurantes a la carte. As diferenças entre os grupos entrevistados estão relacionadas basicamente com a ordem de importância dos fatores que afetam a percepção de qualidade dos clientes. Essas diferenças ocorrem principalmente devido às necessidades particulares de cada grupo, os quais contemplam 'casais sem filhos', 'grupos de amigos', 'família' e 'executivos'. Algumas divergências de maior destaque são apresentadas a seguir:

a) os casais sem filhos que utilizam o serviço de restaurantes a la carte percebem a qualidade desse serviço principalmente através da comida, do atendimento e do ambiente. Esse tipo de cliente procura o restaurante para realizar uma refeição de alta qualidade, saborosa e sofisticada em um ambiente acolhedor e tranqüilo e com atendimento diferenciado.

b) os grupos de amigos dão mais importância à cortesia dos funcionários e ao ambiente agradável.

c) as famílias atribuem maior importância à boa comida, com opções para todos os integrantes, incluindo as crianças, à rapidez no atendimento e às instalações de apoio disponíveis para as crianças.

d) os executivos destacaram maior importância ao cardápio oferecido, ao comportamento do garçom e à resposta rápida do atendimento.

A Figura 2 apresenta o modelo dos determinantes da qualidade percebida dos clientes de restaurantes a la carte identificados através das entrevistas de grupos focados (ver Quadro 3). Os fatores mais importantes são apresentados em negrito.

Observa-se na Figura 2, que todos os determinantes da qualidade percebida dos clientes de restaurantes a la carte identificados podem estar dentro das dimensões da qualidade do serviço, propostas por Parasuraman et al. (1985) (ver Figura 1). O modelo proposto dos determinantes da qualidade percebida tem como base este modelo teórico, contudo, as seguintes modificações foram realizadas baseando-se nos resultados obtidos neste trabalho e em outros estudos da literatura:

As dez dimensões da qualidade e os atributos identificados para o contexto de restaurantes a la carte são apresentados como determinantes diretos das percepções do serviço, afetando indiretamente a qualidade percebida do serviço. No modelo teórico de Parasuraman et al. (1985) estes determinantes afetam também as expectativas. $\mathrm{O}$ modelo proposto não considera estas dimensões como determinantes das expectativas, pois os principais fatores que influenciam as expectativas prévias dos clientes, segundo vários autores (e.g. GIANESI; CORRÊA, 1994; FORNELL et al., 1996) são: a comunicação boca-a-boca; as necessidades pessoais; as experiências anteriores e a comunicação externa ou propaganda.

Dentro dos determinantes das expectativas do serviço, foram incluídos a propaganda e o preço do serviço, fatores de menor efeito na qualidade percebida identificados através das entrevistas, e que não são considerados no modelo teórico proposto por Parasuraman. A propaganda e as referências de avaliadores, além da comunicação boca-a-boca, constituem as fontes de informações em relação ao serviço para os clientes. Através destas informações, das experiências anteriores e das necessidades pessoais, são geradas as expectativas nos clientes. 


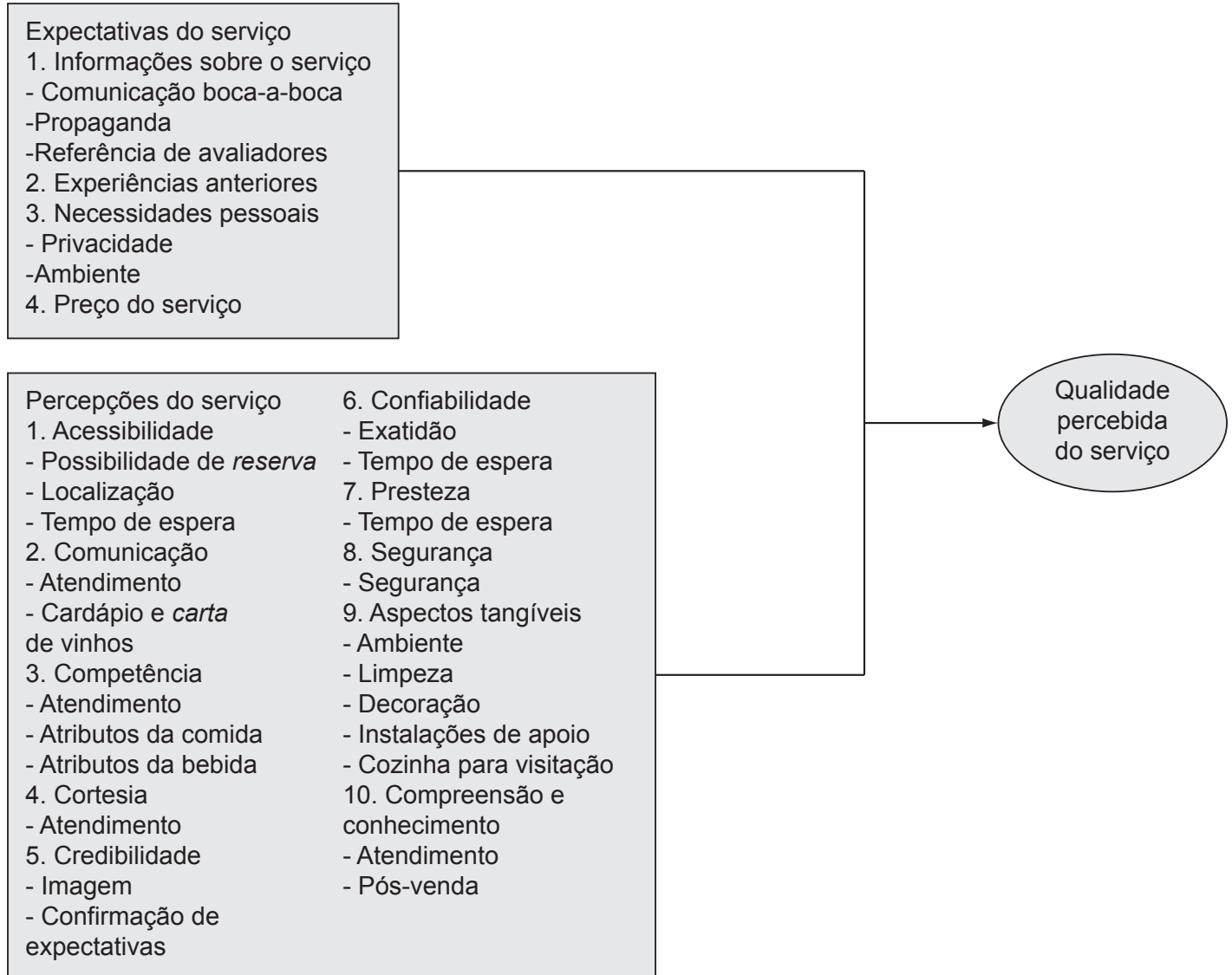

Figura 2. Determinantes da qualidade percebida dos clientes de restaurantes a la carte. Fonte: elaborada pelos autores.

O preço do serviço não foi considerado como um determinante direto da qualidade, mesmo tendo uma forte relação com ela, afetando-a indiretamente através das expectativas do cliente (GRÖNROOS apud SANTOS, 2000). O preço da concorrência, ou qualquer outro preço referencial que o cliente possui através das experiências anteriores, indicação ou referência, gera expectativas em relação ao serviço, as quais são comparadas com a percepção de desempenho deste serviço formando a qualidade percebida.

Embora o modelo proposto por Parasuraman el al. (1985) abranja a maioria dos determinantes da qualidade percebida dos clientes de restaurantes a la carte, a importância deste trabalho reside no fato de que são identificados atributos específicos utilizados pelos clientes para avaliar o serviço de restaurantes a la carte. Portanto, existe a possibilidade de que outros atributos importantes, para avaliar um tipo de serviço específico, não sejam considerados dentro das dimensões de qualidade propostas nos modelos da literatura.

\subsection{Determinantes do preço percebido}

Em relação aos determinantes do preço percebido que foram identificados no estudo, observaram-se convergências nos principais fatores mencionados pelos grupos de clientes de restaurantes a la carte. Da mesma forma que com os determinantes da qualidade percebida, as poucas divergências entre os grupos devem-se principalmente a características particulares de casais sem filhos, grupos de amigos, famílias e executivos.

Os fatores identificados através dos grupos focados e considerados como determinantes do preço percebido pelos clientes de restaurantes a la carte são apresentados na Figura 3.

O modelo proposto dos determinantes do preço percebido, apresentado na Figura 3, sugere que o preço percebido pelos clientes dos restaurantes a la carte é formado a partir da comparação entre o preço esperado ou de referência e o preço real do serviço. O preço esperado é influenciado por um conjunto de atributos ou determinantes. Os fatores considerados de maior importância estão assinalados em negrito.

Analisando as Figuras 2 e 3, observa-se que a maioria dos determinantes importantes na percepção de preço coincide com os determinantes importantes para a qualidade percebida dos clientes de restaurantes a la carte. Este resultado confirma a pesquisa de Chen et al. (1994). Os resultados obtidos na pesquisa desses autores indicam que as dimensões da qualidade do instrumento SERVQUAL afetam o preço percebido para alguns tipos 
Preço esperado

- Qualidade da comida

- Decoração

- Ambiente

- Atendimento

- Instalações de apoio

- Cardápio e carta de vinhos

- Limpeza

- Atributos da bebida

- Privacidade

- Quantidade das porções

Preço real do serviço

Figura 3. Determinantes do preço percebido dos clientes de restaurantes a la carte. Fonte: elaborada pelos autores.

de serviços avaliados. Portanto, poder-se-ia dizer que, para o serviço de restaurante a la carte, os principais determinantes da qualidade percebida também afetam a percepção do preço do serviço.

\section{Conclusões}

A utilização da técnica de grupos focados permitiu identificar os principais determinantes da qualidade percebida e do preço percebido pelos clientes de restaurantes a la carte, considerando a opinião de diferentes grupos de clientes (casais sem filhos, grupos de amigos, família e executivos). O método utilizado (grupos focados) mostrou-se adequado ao objetivo proposto, visto que se conseguiu reunir as percepções dos diferentes grupos de clientes em relação ao assunto pesquisado.

Apesar de existirem pequenas divergências entre os grupos, em relação à ordem de importância dos fatores que afetam a percepção de qualidade e preço dos clientes de restaurantes a la carte, verificou-se a existência de um conjunto de determinantes importantes para os quatro grupos de clientes investigados.

Os principais determinantes da qualidade percebida identificados através das entrevistas de grupos focados foram: os atributos da comida, o atendimento, o ambiente, o tempo de espera, a limpeza, a segurança, as instalações de apoio, o cardápio, a privacidade, os atributos da bebida, a confirmação de expectativas, a exatidão e a decoração. Entre os atributos de influência menor sobre a qualidade percebida foram identificados: a localização, o preço, a possibilidade de reserva, a propaganda, a carta de vinhos e a imagem.

Foi proposto um modelo para representar a qualidade percebida em restaurantes a la carte. Esse modelo baseou-se na proposta de Parasuraman et al. (1985), sendo incluídas algumas modificações no desenho e, principalmente, um maior detalhamento dos elementos do modelo (que foram especificados para o serviço prestado por restaurantes a la carte).

Os principais determinantes do preço percebido, conforme os resultados do estudo, foram: a qualidade da comida, a decoração, o ambiente, $\mathrm{o}$ atendimento, as instalações de apoio, o cardápio, a limpeza, os atributos da bebida, a quantidade das porções, as expectativas prévias e a privacidade. Outros atributos identificados de menor efeito na percepção de preço dos clientes de restaurantes a la carte foram: a segurança, a carta de vinhos, a gorjeta, a imagem, o preço da concorrência, a localização e a propaganda, entre outros. Embora sejam escassos na literatura estudos direcionados à identificação dos determinantes do preço percebido, os resultados desta pesquisa sugerem a existência de relação entre os determinantes da qualidade percebida e do preço percebido dos clientes de restaurantes a la carte, resultado obtido em outras pesquisas da literatura com outros tipos de serviços.

Uma limitação deste estudo, que deve ser citada, é que os resultados obtidos para os determinantes da qualidade percebida e preço percebido são específicos para o tipo de serviço em estudo (restaurantes a la carte) e não podem ser generalizados para outros tipos de serviços sem as devidas adaptações. Uma segunda limitação se refere à metodologia adotada no estudo. A confiabilidade dos grupos focados é maior quando são conduzidos múltiplos grupos, em diversos lugares, com a inclusão de dados de outras fontes ou quando são complementados com a aplicação de uma técnica quantitativa.

Em trabalhos futuros, recomenda-se a validação empírica dos resultados obtidos neste estudo e a identificação das dimensões que determinam a qualidade percebida e o preço percebido por clientes de outros tipos de serviços. 


\title{
Qualitative study of main attributes that determine the consumer quality and price perceptions of a la carte restaurants
}

\begin{abstract}
This paper presents a qualitative study of the determinants of perceived quality and price for la carte restaurant customers. For this, four focus group interviews were conducted joining customers categorized as: couples without children, friends' group, families, and executives. The most important identified determinants of perceived quality were: food attributes, service, ambient, wait time, cleaning, safety, support facilities, menu, drink attributes, privacy, accuracy, decoration, and confirmation of expectations. These determinants were compared with the perceived quality model suggested by Parasuraman et al. (1985) and some modifications were proposed based on the results gathered on the la carte restaurants study and on other evidences presented in literature. On the other hand, the most important determinants of perceived price were: food quality, decoration, ambient, service, support facilities, menu, cleaning, drink attributes, portion amount, previous expectations, and privacy. The results suggest the existence of a relationship between the determinants of perceived quality and perceived price for la carte restaurants customers. These results are compared with other literature studies.
\end{abstract}

Keywords: Perceived quality determinant. Perceived price determinant. La carte restaurants.

\section{Referências bibliográficas}

ANDERSON, E.W.; FORNELL, C.; LEHMANN, D.R. Customer Satisfaction, Market Share, and Profitability: Findings from Sweden. Journal of Marketing, v. 58, n. 3, p. 53-66, Jul. 1994.

BEI, L.; CHIAO,Y. An Integrated Model for the Effects of Perceived Product, Perceived Service Quality, and Perceived Price Fairness on Consumer Satisfaction and Loyalty. Journal of Consumer Satisfaction, Dissatisfaction and Complaining Behavior, v. 14, p.125-140, 2001.

BOLTON, R.N.; DREW, J.H. A multistage model of customer's assessments of services quality and value. Journal of Consumer Research, v.17, p. 375-384, March 1991.

CHADE, J. Ricos pedem ao Brasil que abra setor de serviços a estrangeiros. O Estado de São Paulo, São Paulo,quinta-feira 02 de março de 2006. Disponível em: <http://www.investimentos. sp.gov.br/sis/lenoticia.php?id=140\&c=1>. Acesso em: 15/09/2006.

CHEN, I.J.; GUPTA,A.; ROM, W. A study of price and quality in service operations. International Journal of Service Industry Management, v. 5, n. 2, p. 23-33, 1994.

CRONIN, J. J.; TAYLOR, S. A. Measuring Service Quality: a reexamination and extension. Journal of Marketing, v. 56, n. 3, p. 55 - 68, Julho 1992.

FITZSIMMONS,J.A.; FITZSIMMONS, M.J. Administração de Serviços: operações, estratégia e tecnologia da informação. 4 ed. Porto Alegre: Bookman, 2005. 564 p.

FORNELL,C.; JOHNSON,M.D.; ANDERSON, E.W. et al. The American Customer Satisfaction Index: Nature, purpose, and findings. Journal of Marketing, Chicago, v. 60, n. 4, p. 7-12, Oct. 1996.

GIANESI,I. G. N.; CORRÊA, H.L. Administração Estratégica de Serviços: operações para a satisfação do cliente. São Paulo: Atlas, 1994. 233 p.
GRONROOS, C. A. Service Quality Model and its marketing implications. European Journal of Marketing, v.18, n.4. p. $36-44.1984$.

IBGE. Sistema de Contas Nacionais. Brasil 2003. Rio de Janeiro, 2003. Disponível em:<http://www.ibge.gov.br/home/estatistica/ economia/contasnacionais/2003/contasnacionais2003.pdf $>$. Acesso em: 15/09/2006.

JOHNSTONS, R. The determinants of service quality: satisfiers and dissatisfiers. International Journal of Service Industry Management, v. 6, n. 5, p. 53 - 71, 1995.

KOTLER, P. Administração de Marketing: análise, planejamento, implementação e controle. 4 ed. São Paulo, SP: Atlas S.A., 1996. 676 p.

MIGUEL, P.A.C.; SALOMI, G.E. Uma revisão dos modelos para medição da qualidade em serviços. Revista Produção, São Paulo, v. 14, n. 1, p. 12-30, 2004.

PARASURAMAN, A.; ZEITHAML, V. A.; BERRY, L.L. A conceptual model of service quality and its implications for future research. Journal of Marketing, v. 49, n. 4, p. 41-50, 1985.

PARSA, H. G.; SELF, J. T.; NJITE, D.; KING, T. Why restaurants fail. Cornell Hotel and Restaurants Administration Quarterly, v. 46, n. 3, p.304 - 323, 2005.

PARASURAMAN, A.; ZEITHAML, V. A.; BERRY, L. L. SERVQUAL: a multiple - item scale for measuring consumer perceptions. Journal of Service Quality Retailing, Spring, v. 64, p.12-40, 1988.

RIBEIRO, J. L. D. Grupos Focados: teoria e aplicações. Editor José Luis Duarte Ribeiro. Porto Alegre, RS: FEENG/UFRGS, PPGEP/UFRGS, 2003. 93p.

SANTOS, L. Projeto e análise de processos de services: avaliação técnica e aplicação em uma biblioteca. Florianópolis, 2000. 110 p. Dissertação - (Mestrado em Engenharia de Produção). Programa de pós-graduação em Engenharia de Produção, Universidade Federal de Santa Catarina, dez. 2000. 
SHETH, J.; BANWARI, M.; NEWMAN, B. I. Comportamento do Cliente: indo além do comportamento do consumidor. Traduzido por Lenita M.R.E. São Paulo: Atlas, 2001. 795 p.

WALL, E.A.; BERRY, L. The combined effects of the physical environment and employee behavior on customer perception of restaurant service quality. Cornell Hotel and Restaurant Administration Quarterly, v. 48, n. 1, p.59- 69, 2007.

ZEITHAML, V.A. Marketing de Serviços: a empresa com foco no cliente. 2 ed. Porto Alegre, RS: Bookman, 2003. 536 p.

\section{Sobre os autores}

\section{Maria Auxiliadora Cannarozzo Tinoco}

\section{José Luis Duarte Ribeiro}

Departamento de Engenharia de Produção,

Universidade Federal do Rio Grande do Sul - UFRGS,

Avenida Osvaldo Aranha, 99, $5^{\circ}$ andar, CEP 90035-190, Porto Alegre, RS,

e-mails: maria@producao.ufrgs.br; ribeiro@ producao.ufrgs.br

Agradecimentos: Os autores agradecem à CAPES e ao CNPq pela concessão de bolsas de pesquisa que viabilizaram a realização do trabalho. 
